\title{
Система обходу навчальних перешкод безпілотним повітряним судном
}

(Представлено: д.е.н., проф. Квасніков В.П.)

\begin{abstract}
Вирішується завдання створення системи для імітації навчального польоту безпілотного повітряного судна або дистаниійно пілотованої авіаційної системи між будівлями, задля чого використовується багаторежимне керування польотом иляхом розбиття траєкторії руху безпілотного повітряного судна на декілька ділянок. Гранищі кожної ділянки представлено у вигляді додаткових проміжних пунктів маршруту. Розроблена система використовується для візуалізаиії польоту безпілотного повітряного судна. Сформульовано завдання для системи обходу полігональних перешкод. Розглядається моделювання навчальної польотної траєкторії дистанційно пілотованої авіаційної системи або безпілотного повітряного судна між двома заданими пунктами призначення з обходом перешкод різного розміру; враховано, шзо потрібно звести до мінімуму кількість переміщень у режимі реального часу. Розроблено алгоритм керування польотом безпілотного повітряного судна по заданій траєкторії з одного пункту до іншого. Задану траєкторію пропонується розбивати на декілька більш дрібних частин та визначати границі ичих новостворених частин у вигляді координат пунктів призначення. Розроблено алгоритм та блок-схему алгоритму для здійснення обходження перешкод різного розміру. Проведено моделювання та наведено експериментальні результати. Запропонований метод призначено для реалізації руху по заданій траєкторії з заданою ивидкістю та потужністю, необхідною для передачі інформації. Результати моделювання показують ефективність алгоритму для моделювання польотної траєкторії, ї̈ перепланування під час виявлення перешкод різних форм.
\end{abstract}

Ключові слова: безпілотне повітряне судно; дистанційно пілотована авіаційна система, обхід перешкод; обробка інформації; система керування.

Актуальність теми. Відомо, що задачі планування траєкторії польоту належать до процесу почергового обходження нерухомих об’єктів та їх спостереження [1]. Для розв'язання подібних задач використовуються алгоритми нейромережевого планування, алгоритми 3 використанням графових моделей [2, 3], методи випадкових дерев [4, 5]; як початкові дані вказано координати об'єктів спостереження. Результат - послідовність обходження запланованої траєкторії.

В методах обробки інформації під час планування траєкторії недостатня увага приділяється вибору траєкторії планування польоту 3 обходженням перешкод, інформацію про які не введено в пам'ять безпілотного повітряного судна (БПС) або дистанційно пілотованої авіаційної системи (ДПАС) перед початком польоту. Особливо актуальним це питання постає у випадку наявності рухомих перешкод та зміни динамічного середовища - перепланування траєкторії польоту має відбуватися в автоматичному режимі.

Аналіз останніх досліджень та публікацій, на які спирається автор. Значну кількість наукових робіт присвячено багатьом методам, що застосовуються для обробки даних при керуванні БПС. В літературі найчастіше описують, що найбільш вживаними методами для обробки даних під час керування БПС $є$ алгоритм зворотного розповсюдження помилки та рекурентний алгоритм методу найменших квадратів [6]. Автори А.В. Кузін, Д.В. Курмаков, А.В. Лук'янов та Д.О. Михайлін досліджували нейромережеву реалізацію автоматичного керування посадки БПС [7]. Вчені А.І. Логвін, С.В. Кореванов, В.В. Казін вивчали штучні нейронні мережі, Н.Н. Іванов, І.А. Міранович - нейронні мережі для обробки даних, А.О. Нєдосєкін, К.І. Воронов, О.Б. Максимов, Г.С. Павлов, С.Н. Фролов - займалися нечіткою логікою [8].

Під час планування траєкторії польоту всі методи використовуються залежно від його місії, ступеня автономності руху та стану навколишнього середовища, що детально описується в [9]. У [10] вчені розробили алгоритм керування БПС на прикладі квадрокоптера на базі пласких систем керування. Моделювання та керування БПС із розв'язанням задач, присвяченим квазіавтономності польоту, описано в роботі Буабдаллі [11], алгоритм побудови траєкторії БПС за допомогою введення команд описано в [12], побудова алгоритму навчання 3 використанням нейронної мережі, який засновано на математичній моделі руху БПС, отримала подальший розвиток у [13].

Метою статті $\epsilon$ розробка системи керування траєкторії польоту БПС, що орієнтована на обхід перешкод, інформація про які відома до початку польоту та/або надходить під час польоту; розробка моделі для системи обходу навчальних перешкод, що складається зі статичних та динамічних об’єктів у реальному часі. 
Викладення основного матеріалу. Під час розв'язання задач планування автономного польоту зазвичай розв'язуються три підзадачі: планування польоту, створення траєкторії та керування польотом БПС за заданим маршрутом.

Одночасно під час планування польоту постають задачі, що необхідно розв'язати, будується загальна траєкторія, яку потрібно подолати від початкової точки до кінцевого пункту. Така інформація не завжди $\epsilon$ достовірною i, зазвичай, необхідно використовувати оперативну інформацію в реальному масштабі часу для побудови траєкторії польоту та вирішення польотних завдань.

Відповідно до обраного методу по побудові траєкторії польоту, а також при врахуванні апріорних вхідних даних визначається оптимальний шлях польоту та передаються координати до особи, яка приймає рішення як задачу керування. Обраний крок дискретизації буде впливати на точність рішення, а також безпосередньо на швидкість і точність оптимального рішення.

Методи прямого пошуку використовуються для перевірки точності станів між дискретними вузлами, отриманими за допомогою згладжуючих поліномів. Однак такі методи накладають допоміжні обмеження при нелінійному програмуванні, що потребує додаткових обчислень.

Методи наближення під час планування траєкторії польоту базуються на нейронних мережах, що проводять числові підрахунки шляхом апроксимації кривої траєкторії з нейронною мережею в реальному часі. При цьому траєкторія будується рекурсивно. Однак такий метод не забезпечує необхідної швидкодії, тому що нейронні мережі базуються на еврістичному методі навчання, а отже їх наближення можна використовувати для генерування траєкторії у відомому статичному середовищі.

Пошукові методи дають можливість набагато швидше обробляти інформацію, але їх недоліком $\epsilon$ проблема локального мінімуму апроксимації побудови траєкторії.

Для розв'язання задачі керування необхідно регулювати стан польоту відповідно до заданих координат. Тому особливо важливими є питання побудови алгоритму траєкторії руху з використанням нейронних мереж. Розглянемо задачу керування траєкторії польоту БПС. При цьому додаткові умови будуть такими: врахування руху БПС здійснюється з одного нерухомого пункту до іншого 3 можливими змінами курсу, висоти, швидкості або всіх трьох складових одночасно.

Головна особливість побудови маршруту БПС в реальних умовах під час обходу перешкод $\epsilon$ побудова шляху по кусково-лінійній траєкторії, наприклад, як показано на рисунку 1.

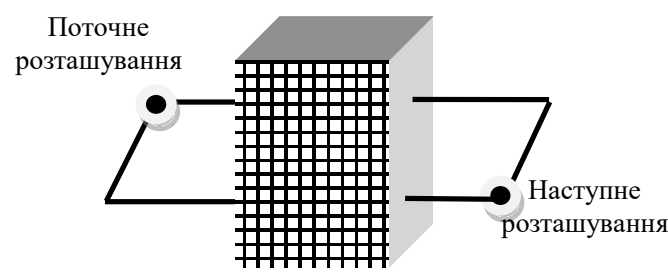

Рис. 1. Велика перешкода на запланованій траєкторії польоту

В цьому випадку необхідно:

- розбити траєкторію польоту на декілька частин, визначивши границі кожної з них у вигляді проміжних пунктів (ПП) траєкторії, саме цим і буде визначатися траєкторія керування за відсутності перешкод;

- $\quad$ у випадку наявності перешкод необхідно визначити додаткові ПП для їх обходу, приклад яких наведено на рисунку 2.

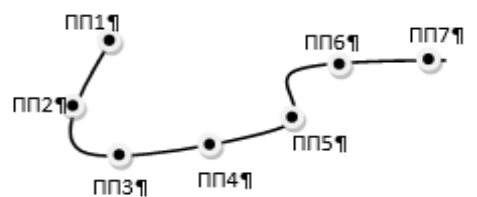

Рис. 2. Приклад розбиття траєкторії на проміжні пункти

Алгоритм роботи. Запропонований алгоритм має два цикли: зовнішній та внутрішній. У зовнішньому циклі відбувається почерговий перегляд всіх ПП. У внутрішньому циклі розглядається кожен ПП та здійснюється перегляд всіх перешкод щодо можливості їх потрапляння на побудовану лінію початкової траєкторії. Вихід з внутрішнього циклу відбувається після перегляду всіх перешкод одного ПП, зовнішній цикл завершується, коли все всі ПП розглянуто. Після завершення роботи алгоритму формується нова траєкторія польоту, до якої будуть входити всі пункти початкової траєкторії та нові призначені пункти обходу перешкод. Такий алгоритм буде виконуватися завдяки побудові траєкторії польоту з отриманням додаткової інформації про нові ПП або перешкоди на створеній траєкторії, блок-схему якого представлено на рисунку 3. 


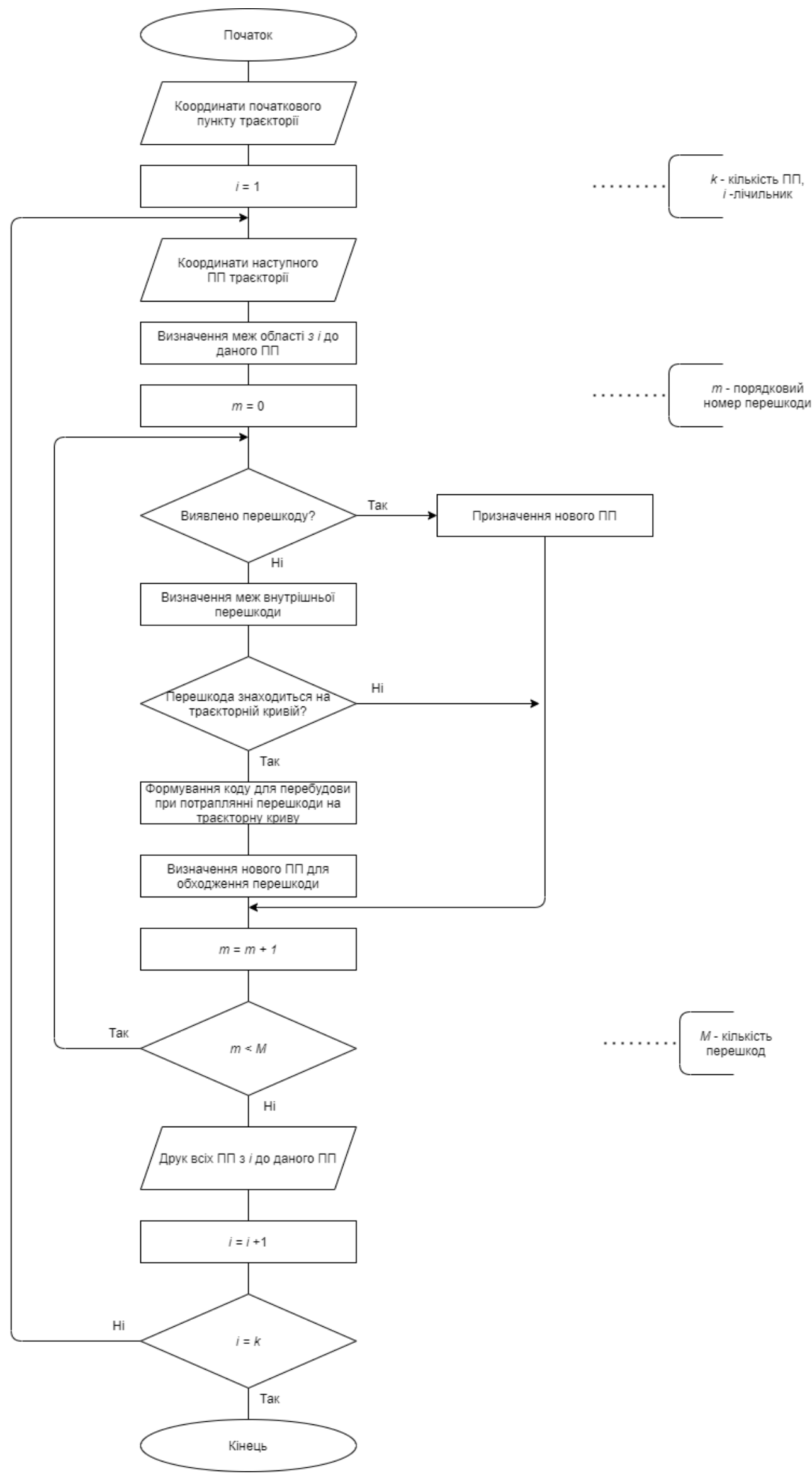

Рис. 3. Блок-схема алгоритму для системи керування траєкторією польоту БПС 
Змінні, що використовуються на блок-схемі:

- $\quad i-$ лічильник, значення якого змінюються від 0 до $k$;

- $\quad k$ - загальна кількість ПП;

- $\quad m$ - порядковий номер перешкоди,

- $\quad M$-загальна кількість перешкод на заданій траєкторії.

Робота алгоритму розпочинається зі зчитування інформації про поточне розташування БПС, а також 3 введення або зчитування координат наступного ПП. Рух з поточного положення до наступного буде відбуватися всередині прямокутної області, що визначається за допомогою поточного пункту з одного боку та наступного ПП - з іншого (рис. 4).

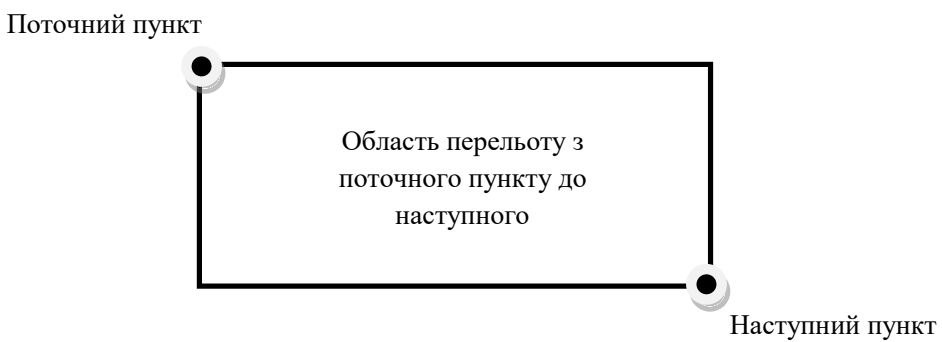

\section{Рис. 4. Гранииі області руху від одного ПП до наступного}

На наступному ПП переходимо до внутрішнього циклу та до блока виявлення можливої перешкоди. Відбувається порівняння відповідних координат перешкоди та траєкторії польоту.

Якщо перешкоди виявлено - задається новий ПП, якщо ні - проводиться визначення границь внутрішньої перешкоди, відбувається аналіз збігу координат перешкоди з траєкторією руху БПС.

Якщо перешкода знаходиться на траєкторії руху - формується програмний код для перебудови та отримання нової траєкторії руху з врахуванням обходу перешкоди і визначається наступний ПП.

Внутрішній цикл працює до того часу, доки не буде враховано всі перешкоди на заданій траєкторії та побудовано новий маршрут з урахуванням усіх перешкод.

Зовнішній цикл працює до того часу, доки не буде здійснено перегляд всіх ПП, що розташовані на запланованій траєкторії руху БПС. Під час виходу з зовнішнього циклу відбувається закінчення роботи алгоритму, результати якого наведено на рисунку 5.

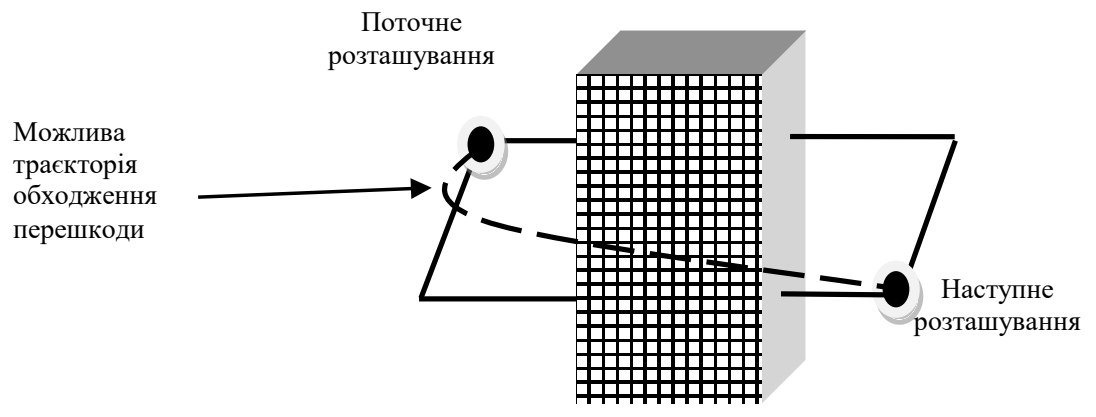

Рис. 5. Результат перебудови траєкторії руху БПС після виконання запропонованого алгоритму

Висновки та перспективи подальших досліджень. Сформульовано задачу керування траєкторією польоту БПС $з$ врахуванням обходження перешкод. Розроблено алгоритм та створено блок-схему алгоритму для системи керування траєкторією польоту БПС. Показано, що під час обходу перешкод розроблений алгоритм формує кусково-лінійну апроксимацію траєкторії обходження перешкод у реальному часі.

В подальшому планується зробити комп'ютерне моделювання траєкторії польоту за розробленим алгоритмом, також провести порівняння та врахувати розмір перешкод для покращення алгоритму побудови оптимальної траєкторії. 
Список використаної літератури:

1. Лєбєдєв Г.Н. Нейромережеве планування дій по обльоту наземних об'єктів групою літальних апаратів / Г.Н. Лебедев, Л.А. Мірзоян // Авіакосмічне приладобудування. - 2005. - № 12. - С. 41-47.

2. Yakovlev K.S. Graph models for solving 2D path finding problems / K.S. Yakovlev, E.S. Baskin // Artificial intelligence and decision making. - 2013. - № 1. - P. 5-12.

3. De Luca F. Advanced Graph Search Algorithms for Path Planning of Flight Vehicles / F. De Luca, G.Guglieri ; in R.Agarwal ed. // Recent Advances in Aircraft Technology. InTech. - 2012. - P. 157-192. DOI: 10.5772/37033

4. LaValle S.M. Motion Planning / S.M. LaValle // IEEE Robotics \& Automation Magazine. - 2011. - Vol. 18. № 1. - P. 79-89. DOI: 10.1109/MRA.2011.940276.

5. Lee D. RRT-Based Path Planning for Fixed-Wing UAVs with Arrival Time and Approach Direction Constraints / D.Lee, D.H. Shim // Proc. International Conference on Unmanned Aircraft Systems (ICUAS). - Orlando, FL, USA, 2014. - P. 317-328.

6. Karayiannis N.B. Artificial Neural Networks / N.B. Karayiannis, A.N. Venetsanopoulos. - Kluwer Academic Publishers, 1993. - P. 12.

7. Пилиньский M. Нейронные сети, генетические алгоритмы и нечеткие системы / М.Пилиньский, Д.Рутковская, Л.Рутковский ; пер. с польск. И.Д. Рудинского. - М. : Горячая линия - Телеком, 2006. - 452 с.

8. Граф М.С. Аналіз існуючих методів обробки інформації в блоці керування безпілотного повітряного судна / М.С. Граф // Вісник Інженерної академії України. - К., 2016. - № 4. - С. 20-22.

9. Янкевич Ю. Применение беспилотных авиационных комплексов в гражданских целях / Ю.Янкевич // Аэрокосмический курьер. - 2006. - № 6. - С. 55-57.

10. Белинская Ю.С. Управление четырехвинтовным вертолётом / Ю.С. Белинская, В.Н. Четвериков // Наука и Образование (МГТУ им. Н.Э. Баумана). - 2012. - № 5 [Электронный ресурс]. - Режим доступа : http://technomag.edu.ru/doc/397373.html.

11. Bouabdallah S. Design and control of quadrotors with application to autonomous flying : dissertation / Bouabdallah Samir. - Lausanne, 2007. - 156 p.

12. Граф М.С. Побудова алгоритму траєкторії руху безпілотного повітряного судна / М.С. Граф // XIII міжнародна науково-практична конференція «ІІРТК» : збірник тез. - К., 2020. - С. 222-223.

13. Graf M. The Construction of the Algorithm Study Based on the Mathematical Model of Motion / M.Graf, V.Kvasnikov // ICTERI. - 2018. - P. 235-242.

\section{References:}

1. Lebedev, H.N. and Mirzoyan, L.A. (2005), «Neural network action planning for the overflight of ground objects by a group of aircraft», Aerospace instrumentation, No. 12, pp. 41-47.

2. Yakovlev, K.S. and Baskin, E.S. (2013), «Graph models for solving 2D path finding problems», Artificial intelligence and decision making, No. 1, pp. 5-12.

3. De Luca, F. and Guglieri, G. (2012), «Advanced Graph Search Algorithms for Path Planning of Flight Vehicles», in Agarwal, R. (ed.), Recent Advances in Aircraft Technology. InTech, pp. 157-192, doi: 10.5772/37033.

4. LaValle, S.M. (2011), «Motion Planning», IEEE Robotics \& Automation Magazine, Vol. 18, No. 1, pp. 79-89, doi: 10.1109/MRA.2011.940276.

5. Lee, D. and Shim, D.H. (2014), «RRT-Based Path Planning for Fixed-Wing UAVs with Arrival Time and Approach Direction Constraints», Proc. International Conference on Unmanned Aircraft Systems (ICUAS), Orlando, FL, USA, pp. 317-328.

6. Karayiannis, N.B. and Venetsanopoulos, A.N. (1993), Artificial Neural Networks, Kluwer Academic Publishers, P. 12.

7. Pylypynskiy, M., Rutkovskaya, D. and Rutkovskiy L. (2006), Neural networks, genetic algorithms and fuzzy systems, translated from Polish by Rudynskiy, I.D., Hotline-Telecom, M., 452 p.

8. Graf, M.S. (2016), «Analysis of existing methods of information processing in the control unit of an unmanned aircraft», Bulletin of the Engineering Academy of Ukraine, K., No. 4, pp. 20-22.

9. Yankevich, Yu. (2006), «The use of unmanned aerial systems for civilian purposes», Aerospace Courier, No. 6, pp. 55-57.

10. Belinskaya, Yu.S. and Chetverikov, V.N. (2012), "Control of a four-rotor helicopter», Science and education, No. 5, MSTU N.E. Bauman, [Online], available at: http://technomag.edu.ru/doc/397373.html

11. Bouabdallah, S. (2007), «Design and control of quadrotors with application to autonomous flying», dissertation, Lausanne, $156 \mathrm{p}$.

12. Graf, M.S. (2020), «Construction of an algorithm of the tracture of an unmanned aircraft», XIII international scientific-practical conference «IIRTK», collection of abstracts, K., pp. 222-223.

13. Graf, M. and Kvasnikov, V. (2018), «The Construction of the Algorithm Study Based on the Mathematical Model of Motion», ICTERI, pp. 235-242.

Граф Марина Сергіївна - аспірант за програмою PhD Національного авіаційного університету.

Наукові інтереси:

- інформаційні технології;

- комп'ютерні науки.

https://orcid.org/0000-0003-4873-548X.

Стаття надійшла до редакції 21.08.2020. 